\title{
The Method of Obtaining Interfacial Catalysis Azerbaijan State University of Oil and Industry
}

\author{
Mikayilova Mehriban Rahil, Mustafayeva Rena Eldar \\ New Chemical Materials and Technologies, "Azerbaijan State University of Oil and Industry", Baku, Azerbaijan
}

\section{Email address:}

rena-babaeva0@rambler.ru (M. R. Eldar)

\section{To cite this article:}

Mikayilova Mehriban Rahil, Mustafayeva Rena Eldar. The Method of Obtaining Interfacial Catalysis Azerbaijan State University of Oil and Industry. Chemical and Biomolecular Engineering. Vol. 4, No. 2, 2019, pp. 37-39. doi: 10.11648/j.cbe.20190402.12

Received: April 3, 2019; Accepted: June 13, 2019; Published: June 26, 2019

\begin{abstract}
Since the reaction proceeds very smoothly under these conditions, the main products are obtained in high yields, including with a high degree of frequency. Increasing the amount of DB18K6 from 0.001 to 0.004 moll and carrying out the reaction at a temperature of $1000^{\circ} \mathrm{C}$ for 70 minutes in the system: 1,2 dimethyl cyclohexane, $\mathrm{KOH}(0.4$ moll), dioxin leads to a gradual increase in the yield of methyl cyclohexane. The maximum yield is achieved with the use of 0.004 moll DB18K6. Secondly, carrying out the reaction at $130^{\circ} \mathrm{C}$ (against $250^{\circ} \mathrm{C}$ ) excluded the formation of by-products, as well as the products of isomerization and tarification. An organic compound of composition $\mathrm{C}_{12} \mathrm{H}_{24} \mathrm{O}_{6}$, belonging to the class of cyclic ethers (crown ethers) and having in a single cycle 6 oxygen atoms arranged in a symmetric manner. It is a white hygroscopic crystal with a low melting point. It is widely used as a specific complexing agent for potassium ions $\mathrm{K}^{+}$. Used reducing agents in a homogeneous medium. Restored ketones in boiling xylene or toluene in the presence of ekvimolar amounts of catalysts, which contributed to the increase in solubility. Diglime, dimethoxymethane and dibenzo-18-crown- 6 were used as catalysts. The last of them leads to better results, however, due to the occurrence of side condensation reactions, the yields of the target products are mediocre. Solid or oily substances form stable complexes with salts (alkali and alkali-metal) soluble in organic solvent. The most commonly used are 18-cray-6, dibenzo-18-crown-6 and the hydrogenation product of the latter - dicyclohexylene-18crown-6. Studying the influence of various factors, it was found that when using potassium hydroxide (0.4 moll) in xylene at a temperature of $130^{\circ} \mathrm{C}$ in the presence of dibenzo-18-crown-6 (DB18K6) (0.0004 moll), the yield of methyl cyclohexane reaches 90 98\%.
\end{abstract}

Keywords: Interphase Catalysis, Methyl Cyclohexane, Diethylene Glycol, Isomerization, Ammonium Salt

\section{Introduction}

It is known that today the method of interphase catalysis (IPC) is the most convenient for industrial implementation. Since the reaction proceeds very smoothly under these conditions, the main products are obtained in high yields, including with a high degree of frequency. In addition, the IPC method is easy to automate and reduces industrial costs $[1,2]$. And most importantly, the IPC method makes it possible to eliminate harmful and poisonous products in chemical processes that lead to environmental pollution [3, 4]. Finally, the IPC method reduces energy costs in the chemical industry. Using the IPC method, we have developed a new, simple and very effective method for producing methylcyclohexin [5]. As a phase transfer catalyst, we used crown ether.
Under traditional conditions, methyl cyclohexane is obtained by dehydrohalogenating 1, 2dihalomethylcyclohexane in the presence of sodium amide in liquid ammonia $\left(\mathrm{NaNH}_{2} /\right.$ liquid $\left.\mathrm{NH}_{3}\right)$, sodium hydride in dimethyl sulfoxide ( $\mathrm{NaH} / \mathrm{DMSO})$ or sodium amide in dimethylformamide $\left(\mathrm{NaNH}_{2} / \mathrm{DMF}\right)$

In addition, the conventional method of producing methyl cyclohexane is a method of conducting dehydrohalogenation in triethylene glycol or without solvent $[6,7]$. However, all these methods have disadvantages, of which the following are significant:

The high cost of reagents used (amides of sodium and potassium, alkali metal hydrides, triethylene glycol, DMSO, DMF);

Carrying out the reaction at high temperature (up to $250^{\circ} \mathrm{C}$ ) lead to isomerization and tarring of the main product. 
In recent years, all these shortcomings are eliminated with the help of the IPC method [8, 10]. However, even under IPA conditions, the method of producing methyl cyclohexane has certain disadvantages. [11-13] In these conditions, Quaternary ammonium bases are used:

The quaternary ammonium salt used as an interphase catalyst is triethylbenzylammonium chloride (TEBAC), under the conditions of an IPC is ineffective due to its instability;

In the case of using crown ethers, potassium tert-butylate is used as a base. And this, in turn, limits the industrial outlook because of the high cost of potassium tert-butoxide.

In order to eliminate the above disadvantages as much as possible, we have developed a simple method for producing methyl cyclohexane in high yields $[9,14,15]$.

\section{Materials and Methods}

The possibility of producing methyl cyclohexane by alkaline dehydrohalogenation of 1, 2dihalomethylcyclohexane in a two-phase heterogeneous system consisting of the starting halide and solid powdered alkali in the presence of crown ether in organic solvents has been studied.

The dehydrohalogenation reaction of 1,2 dihalogenmethylcyclohexane was carried out in a two-phase heterogeneous system consisting of solid alkali powder, IC in an organic solvent.

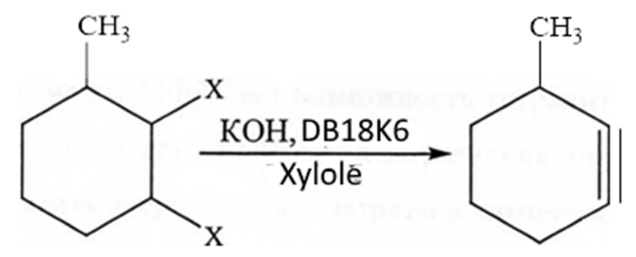

Where $\mathrm{X}=\mathrm{C} 1, \mathrm{Br}$.

Figure 1. The dehydrohalogenation reaction of 1,2 dihalogenmethylcyclohexane.

The following interphase catalysts (IC) were used: crown ethers-dibenzo-18-crown-6 (DB18K6), 18-crown-6 (18K6), pentamethyl-15-crown-5 (PM15K5), tetramethyl-12-crown 4 (TM12K4) and their acyclic analogies are diethylene glycol dimethyl ethers (diglyme), triethylene glycol (triglyme), tetraethylene glycol (tetraglyme), and the widely used quaternary ammonium salt - triethyl benzyl ammonium chloride (TEBAC).

We investigated the patterns of dehydrohalogenation of 1 , 2 dimethyl cyclohexane depending on the nature and concentration of alkali and IC, as well as solvents. The maximum yield of methyl cyclohexane in these conditions is observed in the absence of solvents due to better solubility of DB18K6 and its complex with $\mathrm{KOH}$ in halocarbons and due to the achievement in this case of a high concentration of reagents and catalyst.

In systems with a solvent, the highest yield of the target product is achieved in diglyme (98\%). The yield of methyl cyclohexane, depending on the solvent used, is reduced in the following order:

no solvent $>$ diglym $>$ dioxin $>$ ethylene glycol $>$ xylene

The effect of the nature of crown ethers on the yield of methyl cyclohexane was also studied. It has been established that the crown ethers used for activity are arranged in a row:

\section{DB18K6 $\approx 18 \mathrm{~K} 6>\mathrm{PM} 15 \mathrm{~K} 5>\mathrm{TM} 12 \mathrm{~K} 4$}

The maximum yield of methyl cyclohexane is observed when using DB18K6 and 18K6 (18-crown-6) due to the better complexing ability of these crown ethers with $\mathrm{KOH}$. A gradual decrease in the size of the crown ether cavity during the transition from 18K6 to PM15K5 (Pentamethyl-15crown-5) and further to TM12K4 tatramethyl-12-crown-4 leads to a decrease in the yield of methyl cyclohexane. Without crown ethers, methyl cyclohexane formation is not observed.

\section{Results and Discussion}

The output of methyl cyclohexane is also affected by the change in the concentration of DB $18 \mathrm{~K} 6$ and $\mathrm{KOH}$. Increasing the amount of DB18K6 from 0.001 to 0.004 moll and carrying out the reaction at a temperature of $1000^{\circ} \mathrm{C}$ for 70 minutes in the system: 1, 2 dimethyl cyclohexane, $\mathrm{KOH}$ ( 0.4 moll), dioxin leads to a gradual increase in the yield of methyl cyclohexane. The maximum yield is achieved with the use of 0.004 moll DB18K6.

Similarly, increasing the concentration of $\mathrm{KOH}$ from 0.1 to 0.4 moll increases the yield of the target product. However, an increase in the concentration of $\mathrm{KOH}$ of more than 0.4 moll also causes side processes.

Thus, with the use of crown ethers, we have avoided many of the serious drawbacks that exist in traditional methods. First, instead of flammable and expensive bases (sodium and potassium amides, alkali metal hydrides, potassium tert butylate), the usual commercial alkali was used. Instead of expensive solvents (diethylene glycol, DMSO, DMF) used more economical.

\section{Conclusions}

Crown ethers are used for the concentration, separation, purification and regeneration of metals, including rare-earth metals; for the separation of nuclides, enantiomers; as drugs, antidotes, pesticides; to create ion-selective sensors and membranes; as catalysts in reactions involving anions. Secondly, carrying out the reaction at $130^{\circ} \mathrm{C}$ (against $250^{\circ} \mathrm{C}$ ) excluded the formation of by-products, as well as the products of isomerization and tarification. Studying the influence of various factors, it was found that when using potassium hydroxide $(0.4 \mathrm{moll})$ in xylene at a temperature of $130^{\circ} \mathrm{C}$ in the presence of dibenzo-18-crown-6 (DB18K6) $(0.0004 \mathrm{moll})$, the yield of methyl cyclohexane reaches 90 98\%. 


\section{References}

[1] Selector S. L., Reitman O. A., Sheina L. S., Arslanov V. V., Chegel V. I., Gorbunova Y. G., Enakieva Y. Y., Tsivadze A. Y. // Langmuir Blodgett films of symmetrically substituted tetra15-crown-5-phthalocyanines. Electrochemical and optical properties. // Collection of articles "The structure and dynamics of molecular systems, 2005, issue 12, part 2. p. 181185.

[2] Lapkina L. A., Gorbunova Y. G., Larchenko B. E., Tsivadze A. Y. // Cation-induced supramolecular organization of twoand three-deck REE complexes with tetra-15-crown-5substituted phthalocyanine based on electron spectroscopy data. // Journal. Neorg Chemistry, 2003, t. 48, No. 7, p. 11641173

[3] Arslanov BB, GorbupovaYu. G., Selector S. L., Sheynipa LS, Tselykh OG, EnakiyevaYu. Yu., TsivadzeA. Yu. // Monolayers and Leppgmyur Blodgett Crowd-Substituted Phthalocapiains // Bulletin of the Academy sciences. Ser. Khimich 2004, No. 11, p. $2426-2436$

[4] N. MbembaKiele, C. Herrero, A. Ranjbari, A. Aukauloo, S. A. Grigoriev, A. Villagra, P. Millet. Acid media: Rutheniumbased molecular compounds. // int. J. Hydrogen Energy. 2013. - V. 38. - p. 8590-8596.

[5] Selector S. L., Reitman O. A., Sheina L. S., Arslanov V. V., Chegel V. I., GorbunovaYu. G., EnakievaYu. Yu., TsivadzeA. Yu. // Langmuir films Blodgett of symmetrically substituted tetra-15-crown-5-phthalocyanines. Electrochemical and optical properties. // Collection of articles "The structure and dynamics of molecular systems, 2005, issue 12, part 2. p. 181185.

[6] Vannikov A. B., Grishina A. D., GorbunovaYu. G., EnakievaYu. Y., Krivenko TV, V. Saveliev, V. V., TsivadzeA. Yu. // IR photorefractive composites based on polyimide and tetra-15-kpayn 5 ruthenium phthalocyaninate (11) with axially coordinated triethylenediamine molecules // Zhurn, Fizich. Chemistry, 2006, vol. 8O, No. 3, p. 537-544

[7] M. J. Panzner, F. R. Fronczek, Wesdemiotis, G. R. Newkome.
Share persistent, ruthenium (II)-and iron (II)bisterpyridinemetallodendrimers: synthesis, traveling-wave ion-mobility mass spectrometry and photophysial properties. // New J. Chem.-2012.-V. 36.-P. 484-491

[8] Y.-J. Liu, C.-H. Zenga, H.-L. Huang, L.-X. He, F.-H. Wu. Synthesis, DNA-binding, photocleavage, cytotoxicity and antioxidant activity of ruthenium (II) polypyridyl complexes. // Eur. J. Med. Chem. - 2010. - V. 45. - P. 564-571.

[9] M. Pandrala, F. Li, M. Feterl, Y. Mulyana, J. M. Warner, L. Wallace, F. R. Keene, J. Grant Collins. Chlorido-containing ruthenium (II) and iridium (III) complexes as antimicrobial agents. // Dalton Trans. - 2013. - V. 42. - P. 4686-4694.

[10] Agaguseynova M. M., Mikailova M. R., Formation of Ru nano-composites // IVUZ "Khimiyaikhimicheskaya tekhnologiya” - 2018. - v. 61. - № 3. - p. 45-50

[11] Usacheva T. R., Sharnin V. A., Chernov I. V., Matteoli E. Calorimetric investigation of the reaction of molecular complex formation of 18-crown-6 with D, L-alanine in waterethanol mixtures // J. Therm. Anal. Cal. -2017.-Vol. 1 12.- P. 983-989.

[12] Karbach A., Stemler T., Kopp C., Trommer W. E. Synthesis of novel fluorescent stilbenenitrones via a mild, ligand-free Heck-type reaction of (E)-[4-(1, 3-dioxolan2-yl) styryl] trimethylsilane with benzene diazonium tetrafluoroborate derivatives// Synthesis - 2018. - V. 46. - P. 3103-3109.

[13] Simpson E. M., Ristovski Z. D., Bottle S. E., Fairfull-Smith K. E., Blinco J. P. Modular design of profluorescent polymer sensors// Polymer chem. - 2015. - V. 15. - N6. - P. 2962-2969

[14] Matsuoka Y., Yamato M., Yamasaki T., Mito F., Yamada K. Rapid and convenient detection of ascorbic acid using a fluorescent nitroxide switch// Free Radical Biology and Medicine - 2016. - V. 53. - N 11. - P. 2112-2118.

[15] Yapici N. B., Jockusch S., Moscatelli A., Mandalapu Sr., Itagaki Y., Bates D. K., Wiseman S., Gibson K. M., Turro N. J., Bi Lr. New Rhodamine Nitroxide Based Fluorescent Probes for Intracellular Hydroxyl Radical Identification in Living Cells// Org. Lett. - 2017. - V. 14. - N 1. - P. 50-53. 